\title{
UMA HISTÓRIA DOS POVOS ÁRABES
}

\author{
A HISTORY OF THE ARAB PEOPLES
}

\author{
Marcos Alan S. V. Ferreira ${ }^{1}$
}

Uma História dos Povos Árabes

\author{
Albert Hourani \\ Tradução de Marcos Santarrita
}

São Paulo: Companhia das Letras, 2007, 701p.

ISBN: 978-85-359-0867-1

Perdido entre os diversos livros de história geral da Faculdade de Ciências e Letras da Universidade Estadual Paulista (Campus Araraquara), lembro-me nitidamente da manhã quando me deparei com um livro de capa dourada, com uma bela representação cartográfica histórica da península arábica. Foi ali que começara a explorar um universo novo, que me fizera compreender o diferente - no caso o Oriente Médio - de maneira mais profunda.

Era ali, nos idos de 2002, no calor dos atentados 11 de setembro, que li por uma primeira vez "Uma História dos Povos Árabes”, de Albert Hourani². Muitas outras leituras viriam decorrentes da prática docente e em cada uma delas, sempre tenho tido um novo aprendizado com esse clássico. Adjetivo a obra como clássica pelo fato de estar entre um grupo seleto de manuscritos que resiste ao tempo e proporciona ao leitor mais do que uma visão de história. A obra de Hourani nos permite ver não só os elementos que construíram o mundo árabe, mas também possibilita pensar cenários presentes e futuros.

Essa obra seminal, elementar para qualquer estudioso do Oriente Médio, foi publicada pela primeira vez em 1991. Como fica claro desde o início da obra, seu relato de uma civilização inspira-se grandemente na obra de Ibn Khaldun³ , Muqaddimah. Permeando toda a obra de Hourani, está o conceito de asabiyya, ou seja, "um espírito corporativo

\footnotetext{
${ }^{1}$ Professor no Departamento de Relações Internacionais da Universidade Federal da Paraíba (UFPB). Link para o Currículo Lattes: http://lattes.cnpq.br/4997359951496727.E-mail: marcosalan@gmail.com

${ }^{2}$ Albert Hourani (1915-1993) era libanês de descendência, mas nascido em Manchester, Reino Unido. Durante sua vida foi ligado ao St. Anthony College, Oxford, onde também fundou o Middle East Centre. Também teve posições consulares durante sua vida nas cidades de Cairo, Jerusalém e Londres.

${ }^{3}$ Mesmo ainda pouco conhecido em grande parte do Ocidente, pode-se afirmar sem exagero que Ibn Khaldun (1332-1406) é um dos maiores cientistas sociais de todos os tempos. Nascido onde hoje é a Tunísia, deve-se a ele, por exemplo, o pioneirismo na escrita científica sobre demografia e sociologia. Sua obra Muqadimmah (Prolegômenos), é considerado pelo famoso historiador inglês Arnold Toynbee o maior trabalho de filosofia da história de todos os tempos (Issawi 2017). Nela, Khaldun explica os processos sociais de sua época de maneira singular em seis volumes, compreendendo desde uma sociologia geral até uma sociologia do conhecimento e sociologia política. Embora não se possa afirmar categoricamente tal ideia, muitos veem que as ideias de Nicolau Maquiavel sobre liderança seja em grande parte inspirado nas preposições khaldunianas presentes no Muqadimmah.
} 
voltado para a obtenção e manutenção do poder" (p.17). Nota-se que a coesão e existência do mundo árabe foi fruto de um poder que passara de governantes para os membros do próprio grupo, muitas vezes substituído por uma dinastia que continuaria a conduzir o poder de modo semelhante.

Essa percepção de Hourani é passível de críticas por parte de um viés ocidental democratizante, já que ali ele mostra que o espaço para coesão do mundo árabe dentro de um modelo democrático encontra dificuldades de operacionalização. Porém, penso que deve-se pontuar bem uma crítica dessa magnitude. 0 relato de Hourani e os pormenores de sua obra, mostram bem que o conceito de asabiyya foi o que manteve o mundo árabe em seu ápice político e cultural. Não se trata da defesa de um regime nepotista ou centralizador, mas sim uma constatação dos fatos apresentados pela história. Logo, seria injusto com o pensamento de Hourani - e mesmo de Khaldun - simplesmente colocá-lo como um defensor de um sistema centralizador e corporativista. 0 que ele faz é mostrar como a asabiyya manteve a coesão do mundo árabe, embora igualmente com muitos efeitos colaterais impactantes na história social daquela região que ele não exime de apresentar.

A obra divide-se em cinco partes. Na primeira, o objeto do autor é explanar a história das regiões de língua árabe no início do Islã. Aparece aqui, destarte, alguns elementos que guiam o pensamento do autor. Mais do que explicar a complexidade inteira do mundo muçulmano, a linha mestra do autor é a língua árabe. 0 mesmo justifica isso na introdução, ao dizer que "a história do Magreb é diferente da do Oriente Médio, ou que a história dos países onde o árabe é a língua principal não pode ser vista isoladamente da de outros países muçulmanos. Mas temos de traçar algum limite, e foi aí que decidi traçalo, em parte devido aos limites de meu próprio conhecimento" (p.9). Assim, o leitor não espere encontrar os pormenores sobre a história do Irã, algo que, por exemplo, estará melhor explanado em outras obras seminais como Iran: Empire of the Mind: A History from Zoroaster to the Present Day, de Michael Axworthy. Nem mesmo sobre as idiossincrasias do Islamismo, melhor compreendidas nas obras de Moojan Momen ou Jeffry Halverson 4 .

Mas o que se verá com profunda erudição ainda na primeira parte da obra é como a formação histórica e política de uma religião permitiu posteriormente a construção de um império que sucede Muhammad - o Fundador desta religião - e as cisões que até hoje encontram eco na sociedade árabe, como a divisão entre sunitas, ismaelitas e xiitas - dentre outras denominações explanadas por Hourani. Esta primeira parte permite ao leitor uma compreensão para além das simplificações vistas pela imprensa ou por análises rasas, o que lhe possibilita encontrar a riqueza do impacto histórico de um Manifestante considerado divino por mais de um bilhão de pessoas, assim como os desdobramentos culturais, linguísticos e políticos da religião maometana.

\footnotetext{
${ }^{4}$ Cabe aqui um breve comentário sobre essas obras. No livro de Axworthy (2009), o leitor encontra um repasse detalhado e profundo da Pérsia e Irã desde os tempos de Zoroastro até os dias intranquilos do mandato do presidente Mahmoud Ahmadinejad. Já Moojan Momen, erudito de origem iraniana, é uma das referências na compreensão histórica e metafísica do Islã xiita, especialmente com sua obra seminal $A n$ Introduction to Shi 'i Islam: The History and Doctrines of Twelver Shi ism (MOMEN, 1987). Por sua vez, Jeffry Halverson com sua obra Theology and Creed in Sunni Islam, proporciona um entendimento da filosofia sunita, assim como os movimentos políticos surgidos desta vertente como a Irmandade Muçulmana e os Taliban (ver HALVERSON, 2010).
} 
A segunda parte da obra trata do período do ápice da civilização islâmica até o enfraquecimento da mesma, indo do século XI até XV. 0 fascinante desta parte da obra é como Hourani consegue transportar o leitor para o mundo muçulmano das aldeias, cidades, o papel das elites - às vezes pernicioso, às vezes fundamental para manutenção do império islâmico - e a cultura construída em torno do Islã. É aqui que ele começa também a apresentar de maneira mais profunda como o Islã e a língua árabe fundiram-se com outras culturas vizinhas, como na Índia e Anatólia.

A parte três se dedica em especial a chamada era Otomana, que vai dos séculos XVI ao XVIII, momento central na história árabe ao incluir praticamente toda a região sob a égide de um único império. Este mesmo império seria abalado pela era em que a Europa passa a dominar o mundo, mais especificamente no século XIX. Este período até 1939 ano que eclode a II Guerra Mundial - é objeto da quarta parte da obra.

Ainda que as três partes anteriores sejam obviamente importantes para a compreensão do Oriente Médio, a parte IV guarda uma importância singular para todos aqueles que procuram compreender o Oriente Médio atual. No capítulo 17, Hourani apresenta de maneira ímpar a perniciosa conexão entre os impérios europeus e as elites dominantes, preocupadas tão somente com a manutenção de seus privilégios e que a asabiyya prevalecesse. Nasce ali uma colonização perversa, que divide tribos, separa povos e submete a região aos ditames europeus, em especial franceses e ingleses. Isso é bem apresentado nos capítulos 19 e 20, em que a obra beneficia o leitor na compreensão dos acordos e tratativas que mudariam o mapa político e cultural da região, tais como Acordo Sykes-Picot e Tratado de Sèvres. Adicionalmente, apresenta dados importantes sobre a mudança da estrutura demográfica e cultural que a região sofre nos anos 1914 a 1939. Apenas a título de exemplo, ele demonstra que neste período a população na península Árabe dobra, trazendo pressões sociais relevantes a favor de melhores condições de vida.

Os seis capítulos finais da última parte da obra trazem a mesma intensidade que se retrata na história recente do mundo árabe. Ao retratar o período de 1939 até o final dos anos 1980, Hourani tira o fôlego do leitor com tantos acontecimentos, acordos, mudanças, revoluções e tensões sociais. Mas não podia ser diferente. Embora muitas vezes o nível de detalhe dificulte a compreensão do todo, foram anos centrais na formação política da região. Ali estiveram não somente o mundo árabe como palco da II Guerra Mundial, mas também como protagonista com a crise do petróleo, a crise de Suez, a ascensão do nacionalismo sob a batuta de Gamal Abdel Nasser, dentre outros importantes eventos. Todos esses episódios são explanados por Albert Hourani. Ainda que nem todos eles tenham o nível de detalhe necessário para a compreensão de cada um destes momentos, sua obra é uma porta de entrada para submersões mais profundas em cada um destes momentos da história do Oriente Médio.

Cabe salientar que a obra aqui resenhada é na sua versão de 2007, sendo que ela sofreu modificações importantes com relação ao seu original de 1991. A mais significativa delas foi o posfácio datado de 2002, escrito por Malise Ruthven por ocasião dos 10 anos da obra e que também relata os diversos desdobramentos da história do Oriente Médio após a Guerra do Golfo. Ruthven consegue manter o tom e a qualidade diante da tarefa nada simples de continuar a escrita de um clássico. Ele continua a usar o conceito 
de asabiyya como linha mestra para compreensão da história da região, perpassando acontecimentos post mortem de Hourani, tais como os Acordos de Oslo, o 11 de Setembro e os desdobramentos da Guerra do Golfo.

Ainda que o recorte histórico de Hourani e Ruthven não cheguem até a Primavera Árabe, a conceituação de asabiyya e os pormenores da construção social do Oriente Médio apresentados na obra são centrais para entendermos o que está em jogo nas convulsões que impactam o mundo árabe após a autoimolação de Tarek al-Tayyib Muhammad ibn Bouazizi, em 2010 na Tunísia.

Por fim, considerando-se o conjunto da obra, nota-se que o trabalho de Hourani segue a tradição historiográfica britânica no que há de melhor. Ao condensar com imensa capacidade em 700 páginas mais de 1300 anos de história, o autor procura mais do que simplesmente explicar a história dos povos árabes. Na verdade, ele apresenta um relato da construção de uma civilização que combina o melhor da tradição das ciências humanas do mundo árabe vistas com excelência na obra de Ibn Khaldun, com o estilo de consagrados historiadores britânicos como Arnold Toynbee (em seu Um Estudo de História) e Eric Hobsbawm (com sua trilogia sobre a construção do mundo ocidental desde a Revolução Francesa até o fim da Guerra Fria). Não à toa, assim como as obras dos historiadores britânicos acima mencionados, a obra de Albert Hourani está dentro da seleta categoria de clássicos, haja vista que suas percepções nos permitem compreender o presente e desenhar cenários para o futuro de uma região fundamental para a cultura e a política mundial.

\section{Referências}

AXWORTHY, Michael. Iran: Empire of the Mind: A History from Zoroaster to the Present Day. New York : Penguin, 2009.

HALVERSON, Jeffry. Theology and Creed in Sunni Islam: The Muslim Brotherhood, Ash'arism, and Political Sunnism. New York : Palgrave Millan, 2010.

ISSAWI, Charles. "Ibn Khaldun”, Encyclopedia Britannica, 2017. Disponível em: https:// www.britannica.com/biography/Ibn-Khaldun. Acesso em: 19 Mai. 2017.

MOMEN, Moojan. An Introduction to Shi i Islam: The History and Doctrines of Twelver Shi îsm. Yale : Yale Univ. Press, 1987.

TOYNBEE, Arnold. Um Estudo de História. São Paulo : Martins Fontes, 1976. 